Fecha de recepción: junio 2020

Fecha de aceptación: agosto 2020

Versión final: septiembre 2020

\section{Inclusão Digital e Envelhecimento: uma abordagem centrada no humano e social pelo Design}

Edson José Carpintero Rezende ${ }^{(1)} \mathrm{e}$ Cláudia Fátima Campos ${ }^{(2)}$

Resumo: A terceira idade vem ganhando visibilidade decorrente de um crescimento acelerado, resultante do aumento da longevidade e da queda da fecundidade. Há uma heterogeneidade neste público-alvo, relacionada à presença de possíveis limitações físicas e cognitivas e ao contexto dos países latino-americanos que vivenciam grandes desigualdades sociais. Para diminuir essa desigualdade, é necessário entender suas necessidades e interesses, incentivar o envelhecimento ativo e contribuir para o acesso a seus direitos. Um dos preceitos legais refere-se à educação continuada ao longo da vida. Vale destacar que o analfabetismo está muito presente entre os idosos, fato este que coincide com o analfabetismo digital, observado na pouca habilidade com os computadores. Ao se promoverem ações de inclusão social digital, o idoso pode adquirir conhecimentos e, assim, atualizar-se com a possibilidade de permanecer ou se reinserir no mercado de trabalho. A inclusão digital também favorece o convívio social e familiar do idoso, já que permite o encurtamento de distâncias. Entender este cenário complexo é uma tarefa difícil, mas pode ser facilitada pelo uso de ferramentas do design, úteis para se elaborar um diagnóstico e assim estabelecer diretrizes projetuais que favoreçam a inclusão digital para os idosos. Pretende-se explorar, por meio de uma reflexão teórica, o contexto que envolve a inclusão digital dos idosos e suas peculiaridades. Ao final, espera-se apontar caminhos em que o design contribua para o bem-estar e a qualidade de vida dessas pessoas e apresentar um caso para ilustrar uma experiência exitosa desta relação.

Palavras chave: envelhecimento - design - inclusão digital - qualidade de vida.

[Resumos em espanhol e inglês nas páginas 116-117]

(1) Doutor. Escola de Design da Universidade do Estado de Minas Gerais.

${ }^{(2)}$ Doutora. Escola de Design da Universidade do Estado de Minas Gerais. 


\section{Introdução}

É muito perceptível o quanto o público idoso tem crescido mundialmente, e, acompanhando esta tendência, o Brasil está envelhecendo muito rapidamente (Küchemann, 2012). Tendo em vista a proeminência que os idosos terão em nossas sociedades nas próximas décadas, garantir sua inclusão em todas as esferas e abrir espaços para seu desenvolvimento pessoal será de importância crítica. Nesse sentido, é necessário entender não apenas seus interesses e necessidades, mas também de que maneira eles podem continuar contribuindo para a sociedade a partir de níveis adequados de bem-estar (Huenchuán, 2013). Os dispositivos tecnológicos estão cada vez mais modernos e frequentes em diversas partes do planeta. Em contrapartida, Castells e Cardoso (2005, p. 228) afirmam que "quase a metade dos habitantes da terra nunca fizeram sequer uma ligação telefônica e apenas cerca de 5\% dos latino-americanos têm acesso à Internet em casa". Esta situação díspar é reflexo das desigualdades sociais vivenciados em países em desenvolvimento, como o Brasil.

As desigualdades são percebidas em vários setores e, no que tange à inclusão digital, não é diferente. Em se tratando de idosos, esta realidade ainda é mais sombria, visto que, quando jovens, algumas das tecnologias disponíveis atualmente nem existiam. Por isso, é importante compreender bem este cenário, para que se consiga minimizar algumas dessas questões. Tal compreensão perpassa pelo conceito de idoso, envelhecimento ativo, qualidade de vida e aspectos legais que preveem os direitos destas pessoas.

É também percebível que os atuais desafios do envelhecimento são abundantes e exigem capacidade das organizações não governamentais e governamentais de fornecer eficazmente várias categorias de políticas públicas. É possível observar, cada vez mais, que o desenvolvimento de produtos aponta para a atenção aos aspectos humanos em seus projetos por meio do Design Centrado no Humano, que auxilia no atual cenário e suas complexidades.

A inclusão digital pode ter um papel muito importante na vida dos idosos. Percebe-se que muitos deles transitam pelo universo das tecnologias de informação e comunicação, apresentando melhorias na cognição, nas relações sociais, enfim, no seu bem-estar, de maneira geral. Por meio da tecnologia, é possível a aquisição de novos conhecimentos, que pode resultar em uma atualização capaz de abrir portas no mercado de trabalho ou mesmo favorecer sua permanência. Dentre as diversas vantagens oferecidas, pode-se citar a redução de distâncias quando da comunicação com familiares e amigos que estão longe, inclusive com redução de custos.

Assim, este artigo pretende-se explorar, por meio de uma reflexão teórica, o contexto que envolve a inclusão digital dos idosos e suas peculiaridades e apontar caminhos em que o design contribua para o bem-estar e a qualidade de vida dessas pessoas. Também será apresentado um caso interessante oriundo da Pontifícia Universidade Católica do Rio de Janeiro, para ilustrar uma experiência exitosa desta relação. 


\section{Contextualização e conceitos ligados ao envelhecimento}

A terceira idade vem ganhando visibilidade decorrente de um crescimento acelerado, resultante do aumento da longevidade e da queda da fecundidade (Alcântara, Camarano \& Giacomin, 2016). Tavares e Souza (2012) e Veras (2011) apontam que entre os fatores responsáveis pelo incremento da população idosa estão os avanços tecnológicos, principalmente aqueles relacionados à área da saúde, que permitem melhor qualidade de vida, aumentando a expectativa de vida.

Andrade Neto, Eishima, Bazán e Landim (2010) afirmam que o público idoso tem crescido mundialmente. Com taxa de crescimento de $3 \%$ ao ano, o segmento demográfico de 60 anos ou mais representou, em 2010, 12,3\% da população mundial. Estima-se que este percentual ascenderá a $21,3 \%$ em 2050 , sendo essa estimativa ainda mais elevada para o Brasil, com previsão de que naquele ano a população idosa comporá $29,6 \%$ da população brasileira (Barros \& Goldbaum, 2018). De acordo com Papalia e Feldman (2013), o crescimento mais rápido desta parcela da população será nos países em desenvolvimento, onde em 2013 se concentravam $62 \%$ dos idosos do mundo.

Segundo He, Goodkind e Kowal (2016), a Ásia e a América Latina testemunharão, até 2026, aumento de cerca de 236 milhões de pessoas com 65 anos ou mais. De 2025 a 2050, prevê-se que a população mais velha quase dobre para 1,6 bilhão globalmente, enquanto a população total crescerá apenas $34 \%$ no mesmo período. Na América Latina e no Caribe, a população com idade superior a 60 anos cresceu de 9,6 milhões, em 1950, para 70,9 milhões, em 2015.

No Brasil, o aumento da população idosa está provocando uma modificação no formato da pirâmide populacional, visto que há o aumento da expectativa de vida e o declínio da taxa de fecundidade, o que causa o estreitamento da base da pirâmide etária (Alcântara, Camarano \& Giacomin, 2016; Tavares \& Souza, 2012). Para o Brasil, estima-se que a proporção destas pessoas seja de 13\% em 2020 e 25\% em 2050 (He, Goodkind \& Kowal, 2016). É esperado que o Brasil fique em sexto lugar no ranking mundial de países com a maior população idosa em 2025, com proporção aproximada de $14 \%$. Por essa razão, a terceira idade tem atraído a preocupação de diferentes áreas de pesquisa, por ser um público muito diferenciado, tanto entre si quanto entre outros grupos etários (Ferreira, Maciel, Silva, Sá \& Moreira, 2010). Em se tratando do envelhecimento da população brasileira, percebe-se que, entre a década de 1940 e a de 1960, a população era extremamente jovem (cerca de $52 \%$ abaixo de 20 anos), sendo que as pessoas com idade superior a 65 anos perfaziam menos de $3 \%$. Nesse período, observou-se significativo declínio da mortalidade e leve queda da fecundidade. Em fins da década de 1960, houve declínio rápido da fecundidade e, no início do século XXI, as taxas de fecundidade estavam bem próximas das taxas de reposição, resultando, assim, em um crescimento nulo da população no longo prazo (Carvalho \& Garcia, 2003).

He, Goodkind e Kowal (2016) e World Health Organization (2005) apontam que o ritmo do envelhecimento não foi uniforme. Uma característica distinta do envelhecimento da população global é a sua velocidade desigual nas regiões do mundo e nos níveis de desenvolvimento. A maioria dos países mais desenvolvidos da Europa tem envelhecido há décadas; alguns há mais de um século. Carvalho \& Garcia (2003) descreveram uma com- 
paração entre as mudanças demográficas ocorridas no Brasil e em um país desenvolvido como a Inglaterra. Percebeu-se que este último necessitou de 100 anos para ter declínio de $58 \%$ nas taxas de fecundidade, enquanto no Brasil o percentual de declínio observado foi de $60 \%$, porém, em um prazo de 30 anos. Quando se analisa a proporção de idosos, observa-se que a Inglaterra vivenciou aumento de $56 \%$ nesse seguimento, totalizando $11,6 \%$ de idosos no mesmo prazo de 60 anos (entre 1870 e 1930). Já no Brasil, percebe-se aumento de 5,1 para $8,6 \%$ do número de idosos, perfazendo $69 \%$ também e em um prazo de 30 anos (entre 1970 e 2000). Vale ressaltar que países desenvolvidos como a Inglaterra nunca vivenciaram níveis tão altos de fecundidade como o Brasil.

A Organização Mundial de Saúde considera, para os países desenvolvidos, a idade de 65 anos como a fase inicial da terceira idade. Já em países em desenvolvimento, como o Brasil, o indivíduo é considerado idoso quando chega aos 60 anos, porém, a idade e o processo de envelhecimento possuem significados que ultrapassam a idade cronológica (Castro \& Campos, 2016; Brasil, 2003; Schneider \& Irigaray, 2008; World Health Organization, 2002). Petersen, Kalempa \& Pykosz (2013) relatam que a terceira idade se inicia em torno dos 60 ou 65 anos, variando de acordo com o contexto socioeconômico do país e do próprio indivíduo. Deve-se considerar que a idade cronológica não reflete a verdadeira idade física e biológica, portanto, não há uma idade consensual para o início da velhice. Andrade Neto, Eishima, Bazán \& Landim (2010) ressaltam ainda que a população idosa é muito extensa, chegando a diferenças de 30 anos de idade em um mesmo grupo populacional, fator que torna este grupo muito heterogêneo.

Segundo Carvalho e Garcia (2003), para compreender o processo de envelhecimento populacional, é primordial diferenciar dois conceitos. Um deles diz respeito à longevidade, que corresponde ao número de anos que um indivíduo viverá, referindo-se principalmente às pessoas de uma mesma geração. $\mathrm{O}$ outro refere-se ao envelhecimento populacional propriamente dito, pois está relacionado à mudança na estrutura etária da população.

O envelhecimento é um fenômeno que varia de indivíduo para indivíduo, pois representa uma associação entre fatores genéticos, sociais, culturais e ambientais. A imagem do idoso na sociedade mostra-se dividida em dois grupos: um que é autônomo, ativo, disposto e repleto de sonhos e desejos, e outro que é associado à dependência, à solidão, ao abandono e à falta de sexualidade e grande consumidor de recursos públicos. Essa visão negativa ainda sobressai na atualidade (Camarano, 2004; Ferreira, Maciel, Silva, Sá \& Moreira, 2010). De acordo com Ferreira, Maciel, Silva, Sá e Moreira (2010), ao se avaliar a representação social do idoso diante de alguns termos associados a eles e por eles, percebe-se que envelhecimento está ligado a velho, limitação, doença e inutilidade, muito provavelmente pela alta incidência de doenças crônicas nessa etapa da vida. Essa visão é pobre, pois está limitada aos fenômenos de ordem puramente biológica, não considerando, muitas vezes, referências pessoais e culturais. É necessário construir uma imagem mais positiva do idoso, por meio de uma educação para a velhice nos vários espaços onde estão inseridos. Há que se valorizar o saber dos mais velhos, bem como suas experiências de vida.

Com o intuito de melhor atuação diante das questões que envolvem o envelhecimento, a Organização Mundial de Saúde propõe o envelhecimento ativo, que é o processo de otimização das oportunidades de saúde, participação e segurança, com o objetivo de melhorar a qualidade de vida à medida que as pessoas ficam mais velhas. Representa um processo 
de otimização do estilo de vida do idoso, além de uma expectativa de vida mais saudável, que leva em consideração a saúde mental e também a física (World Health Organization, 2005). O envelhecimento ativo deve ser incentivado ao longo de toda a vida, garantindo uma velhice com qualidade de vida e bem-estar; não deve ser entendido como o fim do desenvolvimento, mas como o início de uma nova fase e um desafio. Assim, promover o envelhecimento ativo mostra-se necessário desde o início da educação do indivíduo, apresentando foco na autonomia e qualidade de vida (Vaccarezzi, Espírito-Santo \& Baptista, 2011).

Não obstante, o envelhecimento ativo depende, além de aspectos como engajamento com a vida, habilidades funcionais e cognitivas, hábitos saudáveis, de condições materiais e de dimensões socioculturais e coletivas sociais que afetam tipos individuais de comportamento e o curso de vida. Esses fatores, conforme Camarano (2014), reforçam a ideia que os idosos não constituem um grupo homogêneo e que a diversidade individual pode se alargar, quanto mais envelhecido for o indivíduo e quanto mais precárias forem suas condições financeiras.

Sendo uma das singularidades do idoso ser um indivíduo diverso, a idade cronológica não consegue representar a categoria do idoso em sua diversidade e em suas dimensões. Portanto, há que se considerar a heterogeneidade relacionada a esta faixa etária-quanto à presença de possíveis limitações físicas e cognitivas, quanto ao idoso institucionalizado e o que vive só e quanto ao contexto dos países latino-americanos-, atrelada à desigualdade social. Na tentativa de diminuir tal desigualdade, é necessário entender de fato as necessidades e interesses dessas pessoas, proporcionar-lhes níveis adequados de bem-estar e qualidade de vida e contribuir para o acesso aos seus direitos e serviços sociais condizentes com a dignidade humana. Seus anseios, de acordo com Camarano (2014), perpassam por projetos de vida estruturados e não apenas por atividades que visam à ocupação de tempo. Sendo assim, para conhecer o idoso, é necessário se aproximar, refletir e apreender sobre esse público dentro do contexto em que ele está inserido.

Várias abordagens sobre a qualidade de vida sugerem tratar-se de um termo complexo, pois está atrelado a uma multiplicidade de questões, inclusive subjetivas. Carrega consigo fatores que envolvem conforto, bem-estar, autoestima, valores, religiosidade, estilo de vida, satisfação com o emprego e/ou com as atividades da vida diária e com o ambiente em que se vive, satisfação nas relações sociais, entre outros, e pode estabelecer uma relação do indivíduo com o contexto cultural e social em que está inserido (Almeida, Gutierrez \& Marques, 2012; Dawalibi, Anacleto, Witter, Goulart \& Aquino, 2013).

\section{Educação e inclusão digital}

Diante de uma sociedade que muitas vezes discrimina o idoso, oferecer a esse público oportunidades para alcançar seu bem-estar físico e emocional, por meio da educação continuada, representa um caminho promissor para se promover esse objetivo. Um dos grandes desafios presentes no campo da aprendizagem em idosos é gerar motivação para que estes se interessem pelo que será ensinado (Unicovsky, 2004). Oliveira, Scortegagna 
\& Oliveira (2009) defendem que a educação, além de minimizar o analfabetismo, é um meio de libertação e transformações nas pessoas idosas, pois permite a reavaliação das características próprias, bem como possibilita um processo de análise e reflexão para esse público. Nessa perspectiva, ressalta-se o papel democrático que a educação possui e todas as possibilidades de mudança que podem ocorrer por meio dela. Para Veras (1995), a educação, seja a continuada ou não, além de direito para o idoso, possibilita: desenvolver novas atividades, desempenhar novos papéis sociais e ampliar sua participação ativa no contexto social e cultural, visando a uma melhoria nas relações interpessoais, minimizando a exclusão social.

A educação ao longo da vida está em muito relacionada ao bem-estar subjetivo, à manutenção da saúde, a uma maior expectativa de vida e à oportunidade de melhores empregos. As pessoas que possuem poucas qualificações estão mais propensas a um envelhecimento precoce, ou seja, quanto mais tempo se permanece exposto a baixos níveis socioeconômicos, mais acelerado poderá ser o processo de envelhecimento (França, 2011). Para participar de forma ativa na sociedade, atualmente é necessário ter domínio das novas tecnologias de computação e de comunicação. Essa inclusão digital representa uma grande preocupação, principalmente no Brasil, visto que o país é marcado por baixo índice de inclusão digital (Doll, 2004).

Inclusão digital é algo que vai além do acesso à internet e às tecnologias de informação e comunicação, pois os conhecimentos digitais obtidos carregam um significado, e esta relação é importante de ser percebida quando promove melhorias no dia a dia dos idosos (Garcia, 2016). Sobre o conceito de inclusão digital, Rosa (2013, p. 37) explicita a aplicação da expressão em diferentes visões. A autora aponta como conceito de inclusão digital "acesso, alfabetização digital ou apropriação das tecnologias" cujo objetivo perpassa o "desenvolvimento econômico, solução de problemas sociais ou garantia de direitos". Segundo a mesma autora, a vertente que relaciona a inclusão digital à solução de problemas sociais confere às tecnologias a função de catalisadoras de mudanças, uma vez que atribui como sinônimas as expressões inclusão digital e inclusão social. Nessa abordagem, a inclusão digital associa-se à garantia de direitos de cidadania, com foco na disseminação democrática do uso das tecnologias em diferentes atividades do cotidiano, como forma de melhorar as condições de vida dos indivíduos nas diversas dimensões.

A inclusão digital pode contribuir com o enfrentamento das desigualdades, pois aqueles que não têm acesso ao universo da informação e das tecnologias digitais interativas são desfavorecidos na sociedade e, portanto, excluídos digitalmente (Cabello, 2014; Seale, 2009). Doll (2004) reitera que, para participar de forma ativa na sociedade, é necessário ter domínio das novas tecnologias de computação e de comunicação. Em algumas situações, estabelece-se um vínculo direto entre inclusão digital e inclusão social (Cabello, 2014; Seale, 2009). A inclusão social digital pode favorecer o envelhecimento ativo e o envelhecimento saudável, proporcionando melhorias na qualidade de vida advindas, por exemplo, do estabelecimento de relacionamentos afetivos, familiares e amigáveis (Bragagnolo \& Deon, 2017).

Seale (2009) desenvolveu um estudo na Inglaterra e percebeu que, opostamente ao conceito de inclusão digital, tem-se que a exclusão digital foi considerada como o não uso de internet nos últimos 3 meses e a falta de acesso à internet em casa. Outro fator ligado 
à exclusão digital foi a idade, principalmente dos idosos. Garcia (2016) aponta que a desigualdade digital merece análise cuidadosa, pois, mesmo diante de problemas sérios de desigualdade relacionados principalmente à pobreza e à distribuição de renda, a exclusão digital pode representar a nova desigualdade social da América Latina.

\section{Questões legais e de cidadania}

De acordo com Tavares e Souza (2012), tornam-se necessárias políticas públicas de saúde, cultura, lazer, educação e inclusão digital para que as necessidades dos idosos sejam atendidas, evitando o seu isolamento social. Muitos foram os avanços nas agendas internacional e nacional na formulação de políticas para a população idosa nas últimas três décadas. O amadurecimento da população brasileira, como reflete Camarano (2014, p. 17), exigiu que o "envelhecimento entrasse na agenda das políticas públicas como um problema". A legislação brasileira incorporou em grande medida as sugestões das assembleias promovidas pela Organização Mundial da Saúde (OMS) e pela Organização das Nações Unidas (ONU), que tiveram papel essencial na análise e comunicação do impacto do envelhecimento na sociedade.

A análise dessas sugestões resultou em um arcabouço legal que reúne uma multiplicidade de instrumentos específicos legislados em prol dos direitos do idoso. Com a implementação da Lei no 8.842, de 4 de janeiro de 1994, que dispõe sobre a Política Nacional do Idoso (PNI), iniciou-se o processo de instauração de políticas no Brasil que objetivam o cumprimento dos ditames legais em proteção ao idoso, presentes no Estatuto do Idoso, na Política Nacional de Saúde da Pessoa Idosa e no Pacto pela Saúde, bem como manter esse público em seu processo de envelhecimento de forma socialmente inclusiva.

Apesar de a Constituição e outras legislações brasileiras estabelecerem prerrogativas legais relacionadas aos direitos dos idosos, segundo Silva e Yazbek (2014), a desigualdade é uma das principais características que se destacam quando se trata de construir a realidade no Brasil. A análise realizada pelas mesmas autoras sobre a situação latino-americana, com base em estudos e documentos publicados pela Comissão Econômica para a America latina e Caribe (Cepal) -a partir das três Conferências Intergovernamentais sobre envelhecimento na América Latina e no Caribe-, indica como necessidade o esforço para se implementar efetivamente políticas orientadas a atingir maior igualdade entre os cidadãos, garantindo proteção social e reconhecimento da cidadania.

Com fundamento no exposto nessas conferências e diante do contingente expressivo da população idosa na América Latina, Silva e Yazbek (2014) esclarecem que os programas, serviços e equipamentos disponibilizados pelo setor público, ainda que representando avanços significativos nos âmbitos federal, estadual e municipal, são insuficientes para equalizar as oportunidades aos cidadãos idosos. A realidade desse cenário no Brasil é um desafio na agenda pública governamental e requer planejamento e adoção de mecanismos com amplitude de cobertura nos setores de saúde, segurança, habitação, educação, entre outros, e uma ação popular de controle democrático e social, por meio da cidadania organizada. 
Em 2014, no relatório da Global Age Watch Index, da organização não governamental Help Age International, que estuda os direitos dos idosos, o Brasil ocupava a $58^{a}$ posição geral. Os indicadores consideraram quatro categorias-chave: garantia de renda, saúde, emprego e educação, e ambiente social. No quesito "emprego e educação", que engloba pessoas empregadas entre 55 e 64 anos e o grau de instrução dos idosos, o país teve o seu pior desempenho, ficando na $68^{\text {a }}$ posição. Essa realidade estabelece a importância de se planejar cuidadosamente políticas para inserção do idoso no âmbito educacional.

Uma ação a ser destacada na Política Estadual de Amparo ao Idoso do Estado de Minas Gerais que pode proporcionar o convívio e inclusão social refere-se à educação continuada ao longo da vida. Como pressuposto nessa área, a lei determina que as instituições acadêmicas estaduais -a saber, a Universidade do Estado de Minas Gerais (UEMG) e a Universidade Estadual de Montes Claros (UNIMONTES)- devem garantir e apoiar a criação de cursos abertos para o idoso, como meio de universalizar o acesso às diferentes formas ao saber (Lei no 12.666, de 04 de novembro de 1997).

\section{Benefícios da inclusão digital}

Para Ordonez, Yassuda e Cachioni (2011), há alguns benefícios importantes quando há uma interação entre idosos e computadores. Dentre eles, podem-se citar: aumento de interação social por meio da internet, estímulo no desempenho cognitivo, formação de novas redes sociais com pessoas com interesses comuns, possibilidade de comunicação com parentes e amigos distantes, além de melhorias em processos psicológicos, tais como a depressão e o bem-estar. Petersen, Kalempa e Pykosz (2013) complementam dizendo que o indivíduo deve envelhecer sem perder a conexão com o mundo ao seu redor, que por sua vez é basicamente digital. Como as tecnologias estão em constante avanço, torna-se necessária a busca contínua por conhecimento. É importante ressaltar a existência de uma importante relação entre autoestima e uso de tecnologia, ao confirmar que a competência de domínio de uma nova habilidade leva ao crescimento da autoestima. A autoestima é capaz de desempenhar uma função importante no processo de aprendizado de novas tecnologias pelos idosos (Castro \& Campos, 2016; Maissiat \& Biazus, 2010).

De fato, ao experimentar o meio digital, a visão do idoso sobre a sua própria velhice começa a ser alterada. O idoso incapaz, inútil e sem autonomia, ao ter sua autoestima recuperada por meio do aprendizado, passa a ser um novo agente social (Oliveira, Scortegagna \& Oliveira, 2009). Os esforços que os idosos fazem no decorrer da aprendizagem convertem-se em superação pessoal (facilita a própria aceitação da condição de idoso), a qual lhes permite desfrutar dos benefícios do aprendizado contínuo e resultados gradativos e efetivos, podendo realçar virtudes na velhice, romper a distância entre a tecnologia e o indivíduo da maturidade. Nessa perspectiva, a educação digital possui a intencionalidade de facilitar a vida diária do idoso e promover mais autonomia e, consequentemente, um envelhecimento mais ativo (Kachar, 2001; Saraiva, 2008).

Embora muitos adultos da terceira idade continuem no mercado de trabalho após se aposentarem, está cada vez maior o número de pessoas com tempo livre para atividades de 
lazer ou busca por conhecimento (Petersen, Kalempa \& Pykosz, 2013). Ao se promoverem ações de inclusão social digital, o idoso tem a chance de adquirir conhecimentos presentes em ambientes digitais e, assim, trilhar um caminho para sua atualização, com a possibilidade de permanecer ou se reinserir no mercado de trabalho. A educação continuada ao longo da vida pode proporcionar esse caminho. Surge, então, a possibilidade do contato com pessoas de outras gerações e do repasse de conhecimentos e experiências adquiridos ao longo da vida. Além disso, pode ser um ótimo veículo para ser utilizado na formação de profissionais que atuam em equipes intergeracionais, pois os idosos podem repassar seus conhecimentos, suas experiências e suas histórias aos mais jovens recém-admitidos em uma empresa, por exemplo (França, 2011). Bragagnolo e Deon (2017) relatam que os idosos que dominam conhecimentos de tecnologia digital estão mais propensos a superar discriminações e situações de baixa autoestima decorrente do não conhecimento dessas tecnologias. Pode ser que haja certo constrangimento dos idosos em relação aos indivíduos das novas gerações, já que estes transitam com facilidade pelo universo digital.

Em contrapartida, a problemática da exclusão social tende a aumentar quando se aproxima a educação do contexto tecnológico. Acredita-se que os idosos se considerem excluídos digitalmente devido ao fato de alguns terem encerrado suas atividades profissionais quando as tecnologias digitais ainda eram incipientes e não representavam exigência social (Bragagnolo \& Deon, 2017). Segundo França (2011), fato importante a se considerar é o analfabetismo, presente em grande número de idosos, fato esse que coincide com o analfabetismo digital, observado na pouca habilidade desse público com os computadores. O analfabetismo digital é um dos grandes desafios enfrentados pelo idoso. Em geral, são indivíduos que não vivenciaram a aplicação dos avanços tecnológicos nas atividades da vida diária, o que faz com que fiquem vulneráveis à inclusão digital.

É muito perceptível que a evolução dos recursos tecnológicos acontece de maneira muito rápida, por isso, a maioria das pessoas não consegue acompanhá-la (Maissiat \& Biazus, 2010). Kachar (2010) comenta que, ao adquirir algumas tecnologias, já se deve ter em mente que em um curto espaço de tempo haverá o estímulo, principalmente midiático, de que uma novidade, disponível no mercado, seja comprada. Concomitantemente ao fenômeno de envelhecimento populacional e aumento contínuo da população de idosos, estabelece-se a grande disseminação dos recursos digitais em todos os espaços da sociedade. Para o idoso, é essencial se relacionar com a tecnologia e compreender como as "coisas" funcionam, uma vez que a evolução das ferramentas digitais que aumentam as capacidades humanas é constante. Para além de conectar as redes sociais, os recursos digitais estão presentes em diversos ambientes da vida, como na casa -desde usar uma torradeira de pão e marcar uma consulta médica a prever as necessidades e lembrar de tarefas importantes a partir de um comando de voz; no lazer-aplicativos de jogos tradicionais de cartas, palavras cruzadas, compras de ingressos para cinemas, teatros e shows; no estudo -o Google, que consegue preencher automaticamente as buscas prevendo o que você quer pesquisar com grande precisão; e em viagens ou simples deslocamento-o aplicativo Waze, que prevê as melhores rotas a partir da sua localização com apenas um toque.

Kachar (2010) relata que, além da questão da inclusão digital, que promove a inclusão social, pode-se pensar na perspectiva da prevenção, na medida em que podem ser estimuladas funções cognitivas em situações específicas de ensino e aprendizagem com pessoas 
de 45 anos ou mais. A partir do desenvolvimento das habilidades para uso das tecnologias, é possível transferir para outras situações semelhantes, como consultar caixas eletrônicos e afins. Há que se ressaltar também que o uso das mídias sociais digitais proporciona uma distração para a população idosa, permitindo que esta parcela da população se torne mais ativa e participativa nas questões sociais, visto que lhes permite que de suas residências realizem compras, se comuniquem, vivenciem possibilidades de lazer e obtenham informações relacionadas a qualquer assunto, favorecendo aquisição de conhecimentos e até mesmo sua inserção social (Felizmino \& Barbosa, 2018).

Para Maissiat e Biazus (2010), dos idosos que transitam bem pelas tecnologias, como por exemplo computadores, caixas eletrônicos e internet, observa-se normalmente maior poder aquisitivo e maior escolaridade. Muitas vezes, os idosos são menos ágeis e as máquinas eletrônicas rápidas para sua realidade. O idoso de hoje gosta de estar inserido na onda tecnológica, quer aprender e conhecer novos equipamentos para realizar ações cotidianas, como pagar contas e fazer compras. Esse grupo de pessoas pode escolher como pretende ocupar seu tempo, por exemplo viajando, conhecendo novas tecnologias, adquirindo produtos e serviços (Petersen, Kalempa \& Pykosz, 2013).

A inclusão digital também favorece o convívio social e familiar dos idosos, ao encurtar distâncias e representar um facilitador na assistência e manutenção da saúde destas pessoas. Com o domínio da informática, mesmo que básica, a pessoa adquire mais independência, além de novos conhecimentos, que a ajudarão na manutenção da saúde mental, criando novas conexões cerebrais e novas formas de pensar. Além disso, a comunicação se torna mais fácil, permitindo a conexão mais prática com a família e os amigos, uma vez que a tecnologia reduz distâncias (Petersen, Kalempa \& Pykosz, 2013). Dentre as inúmeras vantagens do uso de computadores por idosos, podem-se citar o uso de mensagens eletrônicas para a comunicação com familiares e amigos distantes e a possibilidade de fazer compras com comodidade e segurança, sem sair de casa. Poder realizar chamadas de voz e/ou vídeo, faz com que a internet represente um meio econômico com custo menor que uma ligação telefônica tradicional (Maissiat \& Biazus, 2010). Felizmino \& Barbosa (2018) ressaltam que o estímulo ao uso de tecnologias de comunicação e informação incrementou-se quando os idosos perceberam que podiam se comunicar com amigos e parentes em qualquer lugar do mundo.

Tavares e Souza (2012) comentam que a maior parte dos sistemas computacionais de uso geral foi desenhada para usuários jovens, o que dificulta o uso para o público idoso atualmente. De acordo com Kachar (2010), a geração mais nova tem intimidade e atração pelos artefatos tecnológicos, assimila facilmente as mudanças, pois já convive com esses aparatos desde muito novos, explorando os brinquedos eletrônicos e/ou brincando com o celular dos pais. Já a geração adulta e mais velha, de origem anterior à disseminação do universo digital e da internet, não consegue acolher e extrair tranquilamente os benefícios dessas evoluções na mesma presteza de assimilação dos jovens.

Ordonez, Yassuda e Cachioni (2011) mencionam que há também alguns problemas na interação dos idosos com a tecnologia, como, por exemplo, a possibilidade de gerar confusão diante de um número excessivo de informações e de as barreiras digitais promoverem a exclusão de idosos. 


\section{O papel do design neste contexto}

Entender o contexto do envelhecimento é uma tarefa complexa, mas pode ser bem elucidada a partir do uso de ferramentas do design, bastante úteis para se elaborar um bom diagnóstico desta situação e assim estabelecer diretrizes projetuais que favoreçam a inclusão digital para os idosos. As abordagens do design centrado no humano (DCH), como nos apresenta Krippendorff (2000), podem ser adequadas para o planejamento de ações para este público, pois consideram o indivíduo coparticipativo no processo projetual para a obtenção de informações que seriam de difícil acesso por meio de outros procedimentos. Para Bonsiepe (2011), as ações realizadas por meio dessa abordagem requerem compromisso e o uso de métodos que promovam a interação entre as pessoas envolvidas e entre estas, nas etapas do processo de design, por meio da cocriação. É um meio que busca interpretar as necessidades de grupos sociais e elaborar propostas viáveis e emancipatórias, projetando para e com pessoas, tendo o usuário como elemento participativo em todo o processo. O DCH leva em consideração aspectos sociais, físicos e cognitivos dos envolvidos, colocando o usuário no centro do processo influenciando como será o projeto (Krippendorff, 2000). Dessa forma, esse design mais participativo estimula os indivíduos a compreenderem suas próprias necessidades e imprimi-las na solução final do projeto. Ao analisar e correlacionar o discurso de design centrado no humano com a sua aplicação na prática do desenvolvimento de projetos de design, tanto no âmbito da pesquisa quanto na atuação profissional, Chaves, Bittencourt \& Taralli (2013) observaram uma convergência das técnicas para aspectos relacionados ao bem-estar dos indivíduos, sejam estes os usuários, ou as pessoas envolvidas na relação usuário-objeto.

Para Oliveira \& Freire (2015, p. 69), ao depararem com essas possibilidades de atuação, os designers expandem seus significados e conexões, revelando inesperadas dimensões na prática, "chegando às organizações do terceiro setor, aos governos e às comunidades informalmente constituídas, vislumbrando os recursos sociais que podem ser utilizados na proposição de projetos socialmente inovadores".

Governos em todo o mundo têm enfrentado situações emergentes cada vez mais complexas, como populações envelhecendo. As instituições governamentais estão fundadas em nós de relacionamento e informação que precisam ser gerenciados e conduzidos levando o fator humano para a sua centralidade. $\mathrm{O}$ design, em suas possibilidades de intermediar e propor novas conexões, pode ter maior participação e responsabilidade dentro dessas instituições. Assim, em vez de fornecer projetos, programas ou serviços prontos aos receptores, o designer convida esses agentes a transformarem-se em coautores ativos por meio do design centrado no ser humano. O intuito é transformar todos os envolvidos em fontes permanentes de ideias e inovação, independentemente do seu grau de instrução, classe social e habilidade intelectual. Como resultado, iniciativas que emergem de atitude colaborativa e participativa dos afetados podem estar entre os mecanismos mais promissores da mudança da inclusão digital.

Outra abordagem interessante de ser mencionada refere-se à ergonomia. Em situações que envolvem as tecnologias, algumas transformações cognitivas, sensoriais ou físicas, como a diminuição da memória, audição e coordenação motora, comprometem a interação entre o indivíduo idoso e o dispositivo eletrônico. Os níveis de qualidade dentro da usabilida- 
de podem minimizar a ocorrência desses constrangimentos e comprometimentos desses usuários (Castro \& Campos, 2016). Portanto, a inclusão digital do idoso necessita que os componentes de entrada e saída de dados e as interfaces sejam desenvolvidas seguindo os padrões de acessibilidade. Para Tavares e Souza (2012), no processo de envelhecimento, há declínios de saúde que podem comprometer o acesso dos idosos às novas tecnologias de informação e comunicação. Os déficits decorrentes da idade têm implicações no design de interfaces e sistemas técnicos. Assim, seria importante desenvolver interfaces mais acessíveis aos idosos, respeitando alguns critérios de ergonomia e usabilidade.

\section{Aplicação do design no contexto do envelhecimento e da inclusão digital}

Sobre as técnicas de aplicação do design centrado no humano, há possibilidades diversas de abordagens cujo propósito é constituir uma conexão com os envolvidos e compreender melhor as demandas e preferências desse público (Harada, Chaves, Crolius, Fletcher \& Schor, 2016). Uma das maneiras mais eficazes é por meio da observação em campo com usuários. Para Harada e Schor (2016, p. 24), realizar uma profunda observação do usuário in loco e no seu contexto, guiada por conversas informais referidas como "entrevista etnográfica", estabelece vínculo com o indivíduo, aflora a imaginação subjetiva e estimula a criação.

Tendo em vista a necessidade de avançar no campo prático, o que cabe é a reflexão sobre realizações nesse campo da projetação da inclusão digital como promissor para o envelhecimento mais saudável. O design centrado no ser humano com iniciativas de codesign ou design participativo levam designers, cidadãos e especialistas a trabalharem em estreita colaboração com vistas a oferecer melhores projetos aos seus usuários.

Assim, passa-se a expor uma ação do design elaborada como proposta para problemas sociais no contexto educacional relacionados à população idosa, como um exemplo ilustrativo de experiência exitosa da relação do design na formulação de projetos que promovam o acesso e a interação do idoso com os recursos digitais.

Por meio das características de um design mais participativo e social, Damazio, Pina e Ceccon (2017) propuseram instrumentos de consulta às pessoas idosas sobre suas necessidades, bem como a inclusão delas no processo de desenvolvimento de projetos. Esses instrumentos de suporte para a pesquisa -Diário Bipolar e Mapa Relacional- buscavam analisar e avaliar o universo do indivíduo idoso, com o intuito de desenhar soluções em parceria com o idoso que otimizassem sua experiência com o envelhecimento. O Diário Bipolar é um caderno comum, em que eles registraram situações positivas e negativas do seu cotidiano. O Mapa Relacional refere-se a um mapa da Gávea impresso -bairro onde se localiza a PUC-Rio-, no qual os participantes registraram seus principais trajetos pelo bairro e as pessoas com que conviviam.

Como possibilidade de atender grande parte das necessidades identificadas em campo, o estudo das autoras resultou na ideação de um serviço de educação continuada que ofertasse cursos, oficinas e eventos exploratórios, colaborativos e interativos para maiores de 50 anos (Damazio, Pina \& Ceccon, 2017). O projeto, "PUC-Rio mais de 50", fruto da parceria 
com 9 idosos moradores da Gávea, visou, além de atender suas demandas, promover a troca de saberes por meio de cursos sobre os domínios, entre eles o Oficinas Digitais.

O curso Oficinas Digitais foi planejado, estruturado e implantado a partir do interesse dos entrevistados em usar ferramentas digitais para se manterem, fortalecerem e criarem novos vínculos sociais como meio de se conectarem com a realidade do mundo digital. Ele concentra atividades voltadas para o conhecimento, a exploração e o uso prático de ferramentas e serviços digitais e foi inaugurado com o curso Vídeo chamadas por Skype (Damazio, Pina \& Ceccon, 2017).

Para as autoras do "PUC mais de 50", a imersão dos envolvidos em todas as etapas do processo projetual, além de mapear a situação indesejada em sua realidade, possibilitou pensar e repensar uma solução de novas oportunidades e conquistas com um olhar empático.

\section{Considerações finais}

Partimos do ponto de vista de que, além de o envelhecimento populacional ser crescente, uma singularidade do público idoso é ser diverso. Assim sendo, verificou-se que, para conhecer o idoso é necessário, aproximar-se, refletir e aprender sobre esse público dentro da realidade em que ele está inserido. No contexto educacional, o analfabetismo e o analfabetismo digital ampliam ainda mais a diversidade, provocando, nesse sentido, exclusão social. A tríade Design, Envelhecimento e Inclusão Digital apresentou-se efetiva para o desenvolvimento de soluções adequadas a esse problema social, que é crescente. A abordagem centrada no humano, como meio concreto para compreender as demandas, dinâmica diária e relações pessoais de idosos e identificar o que querem e o que precisam é primordial no desenho dos projetos para, de fato, atendê-los.

No entanto, é necessário também envolver o público na avaliação e validação dos projetos. É fundamental desenvolver e oportunizar aos idososiniciativas que fomentam acesso às novas tecnologias e consequente inclusão digital deste público, como forma de possibilitar uma vida ativa e reconhecer sua cidadania.

\section{Bibliografia}

Alcântara, A. de O., Camarano, A. A. \& Giacomin, K. C. (2016). Política nacional do idoso: velhas e novas questões. Rio de Janeiro: Ipea.

Almeida, M. A. B. de., GutIerrez, G. L. \& Marques, R. (2012). Qualidade de vida: definição, conceitos e interfaces com outras. São Paulo: Escola de Artes, Ciências e HumanidadesEACH/US. Recuperado em 24 de fevereiro, 2019 de http://each.uspnet.usp.br/edicoeseach/qualidade_vida.pdf.

Andrade Neto, M. L., Eishima, R. S., Bazán, A. A., Landim, P. C. (2010, outubro). Design para a longevidade: evidências no P\&D Design. Anais do Congresso Brasileiro de Pesquisa e Desenvolvimento em Design, São Paulo, SP, Brasil. 
Barros, M.B.A. \&, Goldbaum, M. (2018). Desafios do envelhecimento em contexto de desigualdade social. Revista de Saúde Pública, 52 (supl 2), 1s-3s. Recuperado em 15 de setembro de 2018 de http://www.scielo.br/pdf/rsp/v52s2/pt_0034-8910-rsp-52-s2-S15188787201805200supl2ed.pdf.

Bonsiepe, G. (2011). Design, cultura e sociedade. São Paulo: Blucher.

Bragagnolo, S. M. \& Deon, M. R. (2017). Inclusão digital para a terceira idade. Revista eletrônica interdisciplinar em gestão organizacional de ciências sociais aplicadas - Visão da Universidade Alto Vale do Rio do Peixe - UNIARP, 6(2), 60-68.

Brasil. Lei n. 8842, de 04 de janeiro de 1994. Dispões sobre a política nacional do idoso e dá outras providências. Recuperado em 15 de novembro de 2018 de http://www.planalto. gov.br/ccivil_03/LEIS/L8842.htm.

Brasil. Lei n. 10741, de 01 de outubro de 2003. Dispõe sobre o Estatuto do idoso. Recuperado em 23 de fevereiro de 2019 de http://www2.senado.leg.br/bdsf/bitstream/handle/ id/530232/estatuto_do_idoso_1ed.pdf.

Cabello, R. (2014). Reflexiones sobre inclusión digital como modalidade de inclusión social. Anais da VIII Jornadas de Sociologia de la UNLP, Ensenada, Argentina. Recuperado em 18 de janeiro de 2019 de http://sedici.unlp.edu.ar/bitstream/handle/10915/50420/ Documento_completo.pdf?sequence $=1$ \&isAllowed $=\mathrm{y}$.

Camarano, A. A. (2004). Os novos idosos brasileiros: muito além dos 60? Rio de Janeiro: IPEA. Recuperado em 27 de dezembro de 2018 de http://www.ipea.gov.br/agencia/images/ stories/PDFs/livros/Arq_29_Livro_Completo.pdf.

Camarano, A. A. (2014). Novo regime demográfico: uma nova relação entre população e desenvolvimento. Rio de Janeiro: Ipea.

Carvalho, J. A. M. de \& Garcia, R. A. (2003). O envelhecimento da população brasileira: um enfoque demográfico. Cadernos de Saúde Pública,19(3), 725-733.

Castells, M. \& Cardoso, G. (2005). A sociedade em rede do conhecimento à acção política. Lisboa: Imprensa Nacional - Casa da Moeda.

Castro, E. V. de \& Campos, L. F. de A. (2016). Os caixas eletrônicos e o usuário idoso: uma discussão sobre a usabilidade e inclusão social. Blucher Design Proceedings, 3181-3191.

Chaves, L. G.; Bittencourt, J. P. \& Taralli, C. H. (2013). O design centrado no humano na atual pesquisa brasileira - uma análise através das perspectivas de klaus krippendorff e da ideo. HOLOS, 29(6), 213-225.

Damazio, V.; Pina, F. \& Ceccon, M. (2017). Design emocional para maiores de 60: contribuições para se viver mais e melhor. Ecovisões projetuais: pesquisas em design e sustentabilidade no Brasil, São Paulo, 37-48.

Dawalibi, N. W.; Anacleto, G. M. C.; Witter, C.; Goulart, R. M. M. \& Aquino, R de C. de. (2013). Envelhecimento e qualidade de vida: análise da produção científica da Scielo. Estudos de Psicologia, 30(3), 393-403.

Doll, J. (2004). A inclusão digital de trabalhadores mais velhos: quais são os desafios? Revista Novas Tecnologias na Educação, 2(1), 1-8.

Felizmino, T. O. \& Barbosa, R. B. (2018). Idosos e dependência de internet: uma revisão bibliográfica. Revista Psicologia, Diversidade e Saúde, 7(1), 1-8.

Ferreira, O. G. L.; Maciel S. C.; Silva, A. O.; Sá, R. C. N. \& Moreira, A. S. P. (2010). Significados atribuídos ao envelhecimento: idoso, velho e idoso ativo. Psico-USF, 15(3), 357-364. 
França, L. H. de F. P. (2011). O envelhecimento populacional e seu reflexo nas organizações: a importância da educação ao longo da vida. B. Tec. Senac: a R Educ. Prof, 37(2), 49-60.

Garcia, L. E. C. (2016). De la inclusión digital a la inclusión social: um estado del arte. 1er Coloquio Interinstitucional de Programas de Doctorado em Ciencias Sociales y Humanas, Colima, México. Recuperado em 9 de janeiro de 2019 de https://www.researchgate.net/ publication/311571936_De_la_Inclusion_Digital_a_la_Inclusion_Social_Un_Estado _del_Arte.

Global AgeWatch Index. (2014) Insight report. London: HelpAge International. Recuperado em 02 de fevereiro, 2019 de http://www.duchodova-komise.cz/wp-content/uploads /2014/10/Global-AgeWatch-Index-2014.pdf.

Harada, F. J. B. \& Schor, P. (2016). Design centrado no humano como método para compreender o problema da autoadministração de medicamentos por idosos com deficiência visual. HFD, 9(5), 18-37.

Harada, F. J. B.; Chaves, I. G.; Crolius, W. A.; Fletcher, V. \& Schor, P. O. (2016). Design Centrado No Humano aplicado: A utilização da abordagem em diferentes projetos e etapas do design. Revista D.: Design, Educação, Sociedade e Sustentabilidade, 8(2), 87-107.

He, W.; Goodkind, D. \& Kowal, P. (2016). An aging world - 2015: international population reports. Washington: Government Publishing Office.

Huenchuán, S. (2013). Perspectivas globales sobre protección de los derechos humanos de las personas mayores, 2007-2013. Santiago: Cepal - Naciones Unidas.

Kachar, V. (2001). A terceira idade e o computador: interação e produção num ambiente educacional interdisciplinar. (Tese de Doutorado em Educação). PUC-SP, São Paulo.

Kachar, V. (2010). Envelhecimento e perspectivas de inclusão digital. Revista Kairós Gerontologia, 13(2), 131-147.

Krippendorff, K. (2000). Design centrado no usuário: uma necessidade cultural. Estudos em Design, 8(3), 87-98.

Küchemann, B. A. (2012). Envelhecimento populacional, cuidado e cidada- nia: velhos dilemas e novos desafios. In Revista Sociedade e Estado, 27 (1), 165-180. Recuperado em 12 de dezembro, 2018 de http://ref.scielo.org/pf3bpd>, acesso 10 jun. 2016.

Maissiat, J. \& Biazus, M. C. V. (2010). Comunicação entre gerações: uso das novas tecnologias de informação e comunicação como meio de inclusão de idosos. In Terra, N. L., Ferreira, A. J., Tacques, C. de O. \& Machado, L. R. Envelhecimento e suas múltiplas áreas do conhecimento (pp. 89-93). Porto Alegre: EdiPUCRS.

Minas Gerais. Lei no 12.666 de 04 de Novembro de 1997. (1997). Política Estadual de Amparo ao Idoso. Assembleia Legislativa de Minas Gerais. Recuperado em 03 de março de 2015 de http://www.sedese.mg.gov.br/em-situacao-de-abuso-e-exploracaosexual/ page/536-lei-12666.

Oliveira, I. C. d'A. \& Freire, K. M. (2015). Cenários futuros como ferramenta para a organização da sociedade civil. Mix sustentável, 1(2) Recuperado em 18 de novembro de 2015 de http://ojs.sites.ufsc.br/index.php/mixsustentavel/article/.

Oliveira, R. C.; Scortegagna, P. A. \& Oliveira, F. S. (2009). Mudanças sociais e sabores: o papel da educação na terceira idade. $R B C E H, 3(3), 382-392$. Recuperado em 18 de novembro de 2015 em http://ojs.sites.ufsc. 
Ordonez, T. N.; Yassuda, M. S. \& Cachioni, M. (2011). Elderly online: effects of a digital inclusion program in cognitive performance. Archives of Gerontology and Geriatrics, 53(2), 216-219.

Papalia, D. E. \& Feldman, R. D. (2013). Desenvolvimento humano. Porto Alegre: Mc Graw Hill/Artmed.

Petersen, D. A. W.; Kalempa, V. C. \& Pykosz, L. C. (2013). Envelhecimento e Inclusão Digital. Extensio: Revista Eletrônica de Extensão, 10(15), 120-128.

Rosa, F. R. (2013). Inclusão Digital como Política Pública: Disputas no Campo dos Direitos Humanos. SUR. Revista Internacional de Direitos Humanos. Rede Universitária de Direitos Humanos, 1(1), 37-55.

Saraiva, C. A. E. (2008). Envelhecer na atualidade: o ensino de informática para idosos. (Dissertação de Mestrado em Psicologia Clínica). Pontifícia Universidade Católica do Rio Grande do Sul, Porto Alegre.

Schneider, R. H. \& Irigaray T. Q. (2008). O envelhecimento na atualidade: aspectos cronológicos, biológicos, psicológicos e sociais. Estudos de Psicologia, 25(4), 585-593.

Seale, J. (2009). Digital inclusion. London: Technology Enhanced Learning. Recuperado em 22 de fevereiro de 2019 de https://pdfs.semanticscholar.org/c57a/bc4a3396b3d60a 59716121ca894768d7fd80.pdf.

Silva, M. R. F. \& Yazbek, M. C. (2014). Proteção social aos idosos: concepções, diretrizes e reconhecimento de direitos na América Latina e no Brasil. Revista Katál, 17(1), 102-110.

Tavares, M. M. K. \& Souza, S. T. C. de. (2012). Os idosos e as barreiras de acesso às novas tecnologias da informação e comunicação. Revista Novas Tecnologias na Educação, 10(1), 1-7.

Unicovsky, M. A. R. (2004). A educação como meio para vencer desafios impostos aos idosos. Revista Brasileira de Enfermagem, 57(2), 241-243.

Vaccarezzi, E.; Espírito-Santo, A. \& Baptista, R. (2011). Envelhecimento ativo: uma forma de ser e de estar. In Uniesep. Saúde e qualidade de vida: uma meta a atingir. Porto: ESEP. Recuperado em 05 de abril de 2016 de http://books.google.com.br/books?hl=ptBR\&lr= \&id $=x r 2 w Q 9 H E L 6 M C \& o i=$ fnd\&pg $=$ PA134\&dq=aging + in + place + conceito\&ots $=M Z y$ 4EDBZC\&sig=T_M26St5J6DPeNdSkRJuGqcxQeY\#v=onepage\&q\&f=false.

Veras, R. (1995). Um envelhecimento digno para o cidadão idoso do futuro. Rio de Janeiro: Relume Dumará.

Veras, R. P. (2011). Estratégias para o enfrentamento das doenças crônicas: um modelo em que todos ganham. Revista Brasileira de Geriatria e Gerontologia, 14(4), 779-786. view/1169/533.

World Health Organization. (2002). Active ageing: a policy framework - A contribution of the World Health Organization to the Second United Nations World Assembly on Ageing. Madri.

World Health Organization. (2005). Envelhecimento ativo: uma política de saúde. Brasília: Organização Pan-Americana de Saúde/envelhecimento_ativo.pdf.

Resumen: La tercera edad viene ganando visibilidad debido a un crecimiento acelerado, resultante del aumento de la longevidad y de la caída de la fecundidad. Hay una hete- 
rogeneidad en este público, relacionada a la presencia de posibles limitaciones físicas y cognitivas, y al contexto de los países latino-americanos que viven grandes desigualdades sociales. Para disminuir esta desigualdad es necesario entender sus necesidades e intereses, incentivar el envejecimiento activo y contribuir para el acceso a sus derechos. Uno de los preceptos legales se refiere a la educación continuada a lo largo de la vida. Cabe destacar que el analfabetismo está muy presente entre los ancianos, este hecho coincide con el analfabetismo digital, observado en la poca habilidad con los ordenadores. Al promover acciones de inclusión social digital, el anciano puede adquirir conocimientos, y así promover su actualización con la posibilidad de permanecer o reinsertarse en el mercado de trabajo. La inclusión digital también favorece la convivencia social y familiar del anciano ya que permite el acortamiento de distancias. Entender este escenario complejo es una tarea difícil, pero puede ser facilitada por el uso de herramientas de diseño, útiles para elaborar un diagnóstico y así establecer directrices proyectuales que favorezcan la inclusión digital para los ancianos. Se pretende explotar, por medio de una reflexión teórica, el contexto que envuelve la inclusión digital del anciano y sus peculiaridades. Al final, se espera señalar caminos en que el diseño contribuya para el bienestar y la cualidad de vida de esas personas y presentar un caso para ilustrar una experiencia exitosa de esta relación.

Palabras clave: envejecimiento - diseño - inclusión digital - calidad de vida.

Abstract: Elderly adults have gained visibility as a result of accelerated growth resulting from increased longevity and decreasing fertility. There is heterogeneity in this target audience related to the presence of possible physical and cognitive limitations, as well as to the context of the Latin American countries that experience great social inequalities. To reduce this inequality, it is necessary to understand the seniors' needs and interests, to encourage active aging and to contribute to the access to their rights. One of the legal precepts refers to lifelong continuing education. It is worth mentioning that illiteracy is very present among the elderly, a fact that coincides with digital illiteracy, observed in their poor ability with computers. By promoting actions of digital social inclusion, the elderly can acquire knowledge and thus promote their updating with the possibility of remaining at or re-entering the labor market. Digital inclusion also favors the social and family life of the elderly, since it allows the shortening of distances. Understanding this complex scenario is a difficult task, but it can be facilitated by the use of design tools, which are useful for making a diagnosis and thus establishing design guidelines that favor digital inclusion for the elderly. We intend to explore, through a theoretical reflection, the context that involves the digital inclusion of the elderly and their peculiarities. In the end, we hope to point out ways in which design contributes to the well-being and quality of life of these people and present a case to illustrate the successful experience of this relationship.

Keywords: aging - design - digital inclusion - life quality.

[Las traducciones de los abstracts fueron supervisadas por el autor de cada artículo] 